\title{
Ventriculitis Caused by Multidrug-Resistant Bacteria in a Medical Intensive Care Unit with Limited Resources
}

\author{
Pedja Kovacevic, Sasa Dragic, Vlado Djajic \\ University Clinical Centre of the Republika Srpska, Medical Faculty, University of Banja Luka, Banja Luka, Bosnia and Herzegovina
}

\section{Abstract}

The widespread use of various devices in the diagnosis or treatment of critically ill neurological patients has led to the more frequent appearance of a new group of meningitis and ventriculitis caused by resistant Gram-negative bacteria or staphylococci. In literature, it has been labeled as health care-associated meningitis and ventriculitis. In our clinical practice (in resource-limited countries), we still have any viable experience neither in the application of these diagnostic and therapeutic tools nor in the handling of complications resulting from their use. However, we have had positive results with the help of the existing guidelines and advice from colleagues in the region (through a video consultation model) while also respecting other factors that reflect our work environment.

Keywords: Central nervous system infections, cerebrospinal fluid drains, cerebrospinal fluid shunt, meningitis, ventriculitis

\section{INTRODUCTION}

The frequently increased use of invasive methods in the treatment of critically ill neurological patients has led to the emergence of a new group of meningitis and ventriculitis, which in the literature has been labeled as nasocomial since they are caused by resistant gram negative bacteria or staphylococci. Due to the mechanism by which they are occurring (placement of one of the devices into the central nervous system - ventriculoperitoneal shunt, external ventricular drain (EVD), intrathecal drug delivery, brain stimulation devices, neurosurgical intervention) it is recommended that they be labeled as healthcare-associated meningitis and ventriculitis. Due to the lack of randomized clinical studies relevant to this topic, valid recommendations are based on the in vitro sensitivity of certain agents to antibiotics, the pharmacodynamic characteristics of particular antibiotics, and the opinion of an expert.

\section{Case Report}

The application of guidelines with a combination of other facts distinguished in developing countries (also in ours) is well illustrated by the case of a patient treated in the Medical Intensive Care Unit of the University Clinical Center of the Republic of Srpska due to health care-associated meningitis

\begin{tabular}{|l|l|}
\hline \multicolumn{3}{|c|}{ Access this article online } \\
\hline Quick Response Code: & Website: \\
& www.ijccm.org \\
& \\
&
\end{tabular}

and ventriculitis after the resumption of external ventricular drain (EVD). A 34-year-old, psychosis-treated woman with a history of poorly controlled arterial hypertension was admitted with an intracerebral hemorrhage located along the frontal horn of the lateral cerebral chamber with a penetration of blood into the brain chamber system and consequent hydrocephalus for which she was promptly fitted with an EVD. We did not go with intraventricular thrombolysis because of the inability to perform a reliable diagnostic test to exclude arteriovenous malformation, and the drainage of the liquor was satisfactory in the $1^{\text {st }}$ day without any signs of infectious syndrome in the patient and with the tendency of recovery of the neurological status. The drain was functioning well for 13 days, and then there was a deterioration in the neurological status of the patient (progression of the disturbance of state of consciousness), a development of febrility, where the drain becomes dysfunctional, and the liquor analysis demonstrated proteinorachy and pleocytosis with the dominance of polymorphonuclears, and we have a positive microbiological isolate from the liquor (Acinetobacter

Address for correspondence: Dr. Pedja Kovacevic, University Clinical Centre of the Republika Srpska, Medical Faculty, University of Banja Luka, Banja Luka, Bosnia and Herzegovina. E-mail: pek0051@yahoo.com

This is an open access journal, and articles are distributed under the terms of the Creative Commons Attribution-NonCommercial-ShareAlike 4.0 License, which allows others to remix, tweak, and build upon the work non-commercially, as long as appropriate credit is given and the new creations are licensed under the identical terms.

For reprints contact: reprints@medknow.com

How to cite this article: Kovacevic P, Dragic S, Djajic V. Ventriculitis caused by multidrug-resistant bacteria in a medical intensive care unit with limited resources. Indian J Crit Care Med 2018;22:814-6. 
baumannii - multidrug resistant), which is only sensitive to colistin and rifampicin. The active drain was immediately extracted, a new one was placed, and we administered colistin intrathecaly and intravenously and rifampicin and continued the vancomycin therapy according to an earlier hemoculture isolate. After 2 days, the patient spontaneously (accidentally) pulled the drain out, and the radiological control showed no deterioration of the hydrocephalus although the signs of inflammation were still maintained (proteinorachy and pleocytosis in the lumbar punctate). In addition, the conservative measures of management of increased intracranial pressure and antibiotic therapy were applied according to the scheme: colistin intravenous, meronem in continued infusion over $3 \mathrm{~h}$ in high doses (Infectious Diseases Society of America [IDSA] 2017 guideline), rifampicin, and vancomycin. After 14 days, antibiotics were excluded during the normalization of laboratory parameters and without signs of infection. Furthermore, after 14 days of repeated lumbar punctures - the findings were satisfactory, the neurosurgeon stated that there was no contraindication for the implantation of the cerebrospinal fluid (CSF) shunt, and the same one was fitted. Three weeks after the neurosurgical intervention of the CSF shunt placement, an endocranial control computed tomography scanner was performed, which was satisfactory. After that, physical rehabilitation of stationary type was carried out.

\section{Discussion}

The frequently increased use of invasive methods in the treatment of critically ill neurological patients has led to the emergence of a new group of meningitis and ventriculitis, which in the literature has been labeled as nosocomial since they are caused by resistant Gram-negative bacteria or staphylococci. Due to the mechanism by which they are occurring (placement of one of the devices into the central nervous system (CNS)-ventriculoperitoneal shunt, EVD, intrathecal drug delivery, brain stimulation devices, and neurosurgical intervention), it is recommended that these are labeled as health care-associated meningitis and ventriculitis. ${ }^{[1]}$ Due to the lack of randomized clinical studies relevant to this topic, valid recommendations are based on the in vitro sensitivity of certain agents to antibiotics, the pharmacodynamic characteristics of particular antibiotics, and the opinion of an expert. ${ }^{[1,2]}$

Most of the studies conducted while monitoring the incidence of CSF infections showed their occurrence in $5 \%-15 \%$ of the cases. ${ }^{[3-6]}$ Confirmation of the infection occurs mainly during the $1^{\text {st }}$ month after the placement of the device. ${ }^{[5-10]}$ The reported incidence of infection in patients with EVDs has ranged from 0 to 22. Factors associated with the increased risk of EVD-associated infections include intraventricular hemorrhage, subarachnoid hemorrhage, cranial fracture with CSF leak craniotomy, ventriculostomy catheter irrigation, and duration of catheterization. It is clear that a greater duration of EVD is associated with an increased risk of infection. ${ }^{[1,6]}$
Till now, there are no randomized trials addressing the optimal treatment of CSF shunt infections. The management of CSF shunt infections should include the removal of the device, external drainage, parenteral antibiotics, and shunt replacement once the CSF is sterile. ${ }^{[1]}$ Intraventricular antibiotics are often useful. ${ }^{[1]}$ In 2017, the IDSA published guidelines for the management of health care-associated ventriculitis and meningitis.

If there is any doubt or confirmation of infection in any CNS device, it should be removed immediately. ${ }^{[1]}$ Regarding the return of the device, there are opinions that this should be done when we are sure that there is no infection and that, until then, the external drain is placed, if necessary.

In antibiotic treatment, it is advised to adapt empirical treatment to the local microbiological map (in vitro susceptibility of antibiotics) if there is no positive isolate and an antibiogram. In empirical treatment for health care-associated meningitis and ventriculitis, it is advised to introduce vancomycin with antipseudomonal beta-lactam (cefepime, ceftazidime, or meropenem). If possible, it is important to monitor the concentration of vancomycin in the blood. If hypersensitivity to beta-lactam or meropenem is suspected, it is suggested to introduce ciprofloxacin or aztreonam. If there is an isolate, then the therapy should be conducted in accordance with a culture and antibiogram. Colistin or polymyxin B (intravenous and intraventricular) is recommended in resistant Acinetobacter strains on meronem and to include a prolonged infusion of meropenem (each dose in a prolonged infusion of $3 \mathrm{~h}$ ).

We administer antibiotics intraventriculary as an adjunct therapy to intravenous one. Intraventricular antibiotics may be useful in the following settings: failure of parenteral therapy to sterilize the CSF, other evidence that the patient is responding poorly to systemic antibiotics, the presence of highly resistant organisms susceptible only to antibiotics with poor CSF penetration, and circumstances in which shunt devices cannot be removed.

If the therapy is given intraventricularly, it is recommended that the EVD be closed for 15-60 min while therapy is being administered. There is controversy about the dosing of this type of drug and this should be based on the concentration of the drug in the CSF, the size of the chamber system, and the daily loss in the drain. The duration of therapy, in most available sources, is recommended to be 14-21 days and in cases of repeated isolates in cultures, at least 10-14 days after a negative culture of the liquor. During this time, antibiotic therapy continues.

\section{Declaration of patient consent}

The authors certify that they have obtained all appropriate patient consent forms. In the form the patient(s) has/have given his/her/their consent for his/her/their images and other clinical information to be reported in the journal. The patients understand that their names and initials will not be published and due efforts will be made to conceal their identity, but anonymity cannot be guaranteed. 


\section{Financial support and sponsorship}

Nil.

\section{Conflicts of interest}

There are no conflicts of interest.

\section{RefEREnCeS}

1. Tunkel AR, Hasbun R, Bhimraj A, Byers K, Kaplan SL, Michael Scheld W, et al. 2017 infectious diseases society of America's clinical practice guidelines for healthcare-associated ventriculitis and meningitis. Clin Infect Dis 2017;64:e34-e65.

2. Tunkel AR, Hartman BJ, Kaplan SL, Kaufman BA, Roos KL, Scheld WM, et al. Practice guidelines for the management of bacterial meningitis. Clin Infect Dis 2004;39:1267-84.

3. Mayhall CG, Archer NH, Lamb VA, Spadora AC, Baggett JW, Ward JD, et al. Ventriculostomy-related infections. A prospective epidemiologic study. N Engl J Med 1984;310:553-9.

4. McGirt MJ, Zaas A, Fuchs HE, George TM, Kaye K, Sexton DJ, et al.
Risk factors for pediatric ventriculoperitoneal shunt infection and predictors of infectious pathogens. Clin Infect Dis 2003;36:858-62.

5. Conen A, Walti LN, Merlo A, Fluckiger U, Battegay M, Trampuz A, et al. Characteristics and treatment outcome of cerebrospinal fluid shunt-associated infections in adults: A retrospective analysis over an 11-year period. Clin Infect Dis 2008;47:73-82.

6. Piatt JH Jr., Carlson CV. A search for determinants of cerebrospinal fluid shunt survival: Retrospective analysis of a 14-year institutional experience. Pediatr Neurosurg 1993;19:233-41.

7. Renier D, Lacombe J, Pierre-Kahn A, Sainte-Rose C, Hirsch JF. Factors causing acute shunt infection. Computer analysis of 1174 operations. J Neurosurg 1984;61:1072-8.

8. Younger JJ, Simmons JC, Barrett FF. Operative related infection rates for ventriculoperitoneal shunt procedures in a children's hospital. Infect Control 1987;8:67-70.

9. Quigley MR, Reigel DH, Kortyna R. Cerebrospinal fluid shunt infections. Report of 41 cases and a critical review of the literature. Pediatr Neurosci 1989;15:111-20.

10. Kontny U, Höfling B, Gutjahr P, Voth D, Schwarz M, Schmitt HJ, et al. CSF shunt infections in children. Infection 1993;21:89-92. 